\title{
Encountering the pedagogy of live and interactive architectural projects
}

\author{
Annabel Pretty, Peter McPherson \\ Unitec Institute of Technology, New Zealand \\ School of Architecture \\ apretty@unitec.ac.nz | pmcpherson@unitec.ac.nz
}

The use of the word "live" as a prefix for a project, is a thought-provoking, and perplexing concept; does one assume that all other projects are dead?

Or is it that "(a)live," in the studio build paradigm, is about the currency and value of the moment? Or is it that one is operating outside of normative architectural academia, and is therefore (a)live?

Untangling the meta meaning of the verb "live" and then juxtaposing it with the word "interactive" could draw the reader to the conclusion that we are talking about a nonmomentary or continuous two-way transfer of information - often as not between the student, the lecturing staff and external agencies (in many cases real clients). It is this existence between the borderland of academia and practice that this chapter hopes to unpack and clarify.

In Architecture Live Projects: Pedagogy into Practice, Chandler states:

if we accept vagueness as inevitable then 'live' may simply mean 'engaging with external agencies outside the academy.'

Live studio and interactive build projects often have a complex interwoven relationship and can be somewhat contradictory by nature. They must be real enough for the as yet un-qualified architectural student, while being generally small scale, somewhat selfsufficient in nature, somewhat self-directed, but with enough complexity of real-world learning, plus the potential for live or real clients.

These elements entwined with inter-cultural dynamics of student groups create a fertile

\footnotetext{
I Alan Chandler, "Building Is Also a Verb”, in Architecture Live Projects: Pedagogy into Practice, ed. Harriet Harriss and Lynnette Widder (Oxon: Routledge, 20I4), 68.
} 
ground for complex issues to be raised about the nature of buildability and practicality and the nature of a practicing architect. These inter-cultural dynamics are often amplified within the architecture schools as, within the globalised New Zealand paradigm of the super-diverse cities, currently more than quarter of New Zealanders are born overseas. This adds complexity to the nature of the student body, and the way in which lecturing staff construct studio live briefs.

Live studio projects can become very close to architectural practice as seen by the Burnham and Wallis paper which covers threshold concepts as framework to analysis learning by making (LBM), synonymously known as studio live projects. They propose the concept of a "portal" to pass through, to enable the transformative thinking necessary for a student to progress with the translation of an idea into a finished project. Case studies and 20 years of LBM inform the framework. They propose the dual concept of "bounded" - the limiting factors expressed by a brief both internally (within the student or student group) and externally (lecturers and clients) - and the "self-reflexive" learner who needs time to consolidate learning and apply it to their own circumstances.

Conversely, live projects can also sit within the conceptual sphere and be more speculative within their resolution, such as Davis's paper on the triple focus of the tyranny and vagueness associated with the architectural academy, the profession and the market. - a narrative viewpoint of a case study within the University of Auckland. This project moves from the speculative design realms into the formally $\mathrm{I}: \mathrm{I}$ design build project, albeit the project was unable to be realised hence the narrative discussion. The conceptual and speculative are further delved into via Rieger's paper, the multi-sensory augmented liminal space that is bounded by the physical and the digital realms. His positioning statement is that the current situation of virtual reality technology interfaces in a tactile manner, within a case study at University of Auckland. The conclusion redefines one's interactivity between the physical, the sensory and the digital spheres. Manfredini's paper on the public space bounded within the shopping mall, as described by social digital media, sits within the interactivity domain of these themes - specifically, in relation to the interactive nature of Instagram's spatially sourced data, and the hashtag of place tagging within the context of the shopping mall environment within the eight largest malls within the greater Auckland environment.

The diverse manner in which lecturing staff formulate, manage and critique these variously named "live project," "learning by making," "design build," or "workplace integrated learning (WIL)" projects are born out within the case studies included within this chapter, and more specifically with Norrie, Grainger, Elliot, Long, and Woods. They describe a design build within a binary modality of scale and usability constructed with bamboo - the resultant project both a think tank and a large-scale public artwork - defined by University of Tasmania's (UTAS) LBM modality and WIL. Discussion of the case study is in terms of the pedagogy of Christopher Frayling's Into/For /Through Design as a framework, all of which adds to the multi-layered understanding of the live project. These papers cover a vast range of hybrid or amalgam issues, not least: problem solving of materials and construction; exposure to a wide range of people implicated within the greater architectural field; and potential client situations (often being paired with an activation partner). The papers include aligned processes such as fundraising, developing 
marketing, running a budget, social media promotion - all of which rarely raise their head within the normal everyday studio typical brief. Lastly but probably most importantly is the ability for students to build I:I on a large scale project, moving from the speculative notions within many of the traditional studio briefs to the quite tangible build, i.e., potential architecture. Perhaps the most important issue is this notion of architecture becoming more aligned and centered with materials/craft/making within an (a)live project, something which architecture often has moved away from. It requires the intersection of the idea or notion of the "master craftsman/builder" and the promise of BIM (Building Information Modelling) to return architects to this central role as opposed to sitting on the fringe, as is touched on lightly in Rieger's paper.

In "Educating the 2 I st Century Architect: Complexity, Innovation, Interdisciplinary

Methods and Research in Design," Jenson states, "Architecture programmes must seek to educate innovative individuals within a common ideological framework, constituted by and relating to the needs of their surrounding community."2

The interactive component of the equation, of the live studio build, follows many guises both within the dynamics of group work and the interdisciplinary nature of working with many internal and external clients. The student as the potential architect takes the role of the enabler and facilitator who empowers others. It is this axiological collaboration as a positive experience, which is truly the value for the participating student.

In "What Belongs to Architecture, Teaching Construction among Live Projects," Widder states, "The experiences of teamwork and physical labor, and of quickly resolving complex, multivariable problems in a spatial context so that work can proceed, reinforce different ways of understanding architecture than the heroic loneliness of the traditional studio or the temporal disjunction of late-night CAD monkeying."3

Measuring the impact of the variously named projects - live, learning by making, design build, workplace integrated learning - is about the currency and value of the triumvirate of student, lecturer, client. Perhaps one can look no further than to considering the fact that speculative projects become (a)live once they have broken free of the confines of the paper/ drawing board / computer and into reality. (A)live is the paradigm of the architect not the lonely or isolated work in the atelier garret, or as Widder states, the "heroic loneliness." (A)live is about reality, and reality provides tangible reasoning for designing, and removes places for the designer to hide, often as not encountered within the speculative large scale architectural project within some studio projects, as generally a student cannot truly create proof of concept. (A)live brings objects and people with which to interact, and positions the learning of the student outside of the academic institute and into the community.

This chapter hopefully goes some way towards covering the various theoretical models or leitmotifs with which to measure the impact of live and interactive projects - even though it may not appear truly successful in the eyes of the students until they are far enough away from the project both literally and metaphorically to understand the "self-

\footnotetext{
2 Michael K. Jenson, "Educating the 2 I st Century Architect: Complexity, Innovation, Interdisciplinary Methods and Research in Design", in Design Studio Pedagogy: Horizons for the Future, ed. Ashraf M. A. Salama and Nicholas Wilkinson (Gateshead: The Urban International Press, 2007), 48.

${ }^{3}$ Lynnette Widder, "What Belongs to Architecture: Teaching Construction among Live Projects", in Harriss and Widder, Architecture Live Projects, 32.
} 
reflexive" modality necessary. Whereas, for the lecturer measuring impact is much more client driven and pragmatic, perhaps less speculative, and of course the client has a wholly different perspective on the resultant architectural intent. (A)live is the artefact as a tangible architectural proposition, and the processes with which to arrive at that point. As Shiel states in Radical Pedagogies: Architectural Education and the British Tradition, "They must construct realities, defend the vulnerability of embryonic ideas, and devote valuable time to play, experiment and fail." 4

\section{To cite this article:}

Pretty, A., McPherson, P. (20I7), Encountering the pedagogy of live and interactive architectural projects, The Journal of Public Space, 2(3), Special Issue, 63-66, DOI: I0.5204/jps.v2i3.I I4

This article has been accepted for publication in The Journal of Public Space. Please see the Editorial Policies under the 'About' section of the journal website for further information.

\footnotetext{
${ }^{4}$ Bob Sheil, "The After Life", in Radical Pedagogies: Architectural Education and the British Tradition, ed. Harriet Harriss and Daisy Froud (Newcastle upon Tyne: RIBA Enterprises, 20I5), I 10.
}

66 | The Journal of Public Space, 2(3), 2017 | Special Issue | ISSN 2206-9658

(c) Queensland University of Technology 